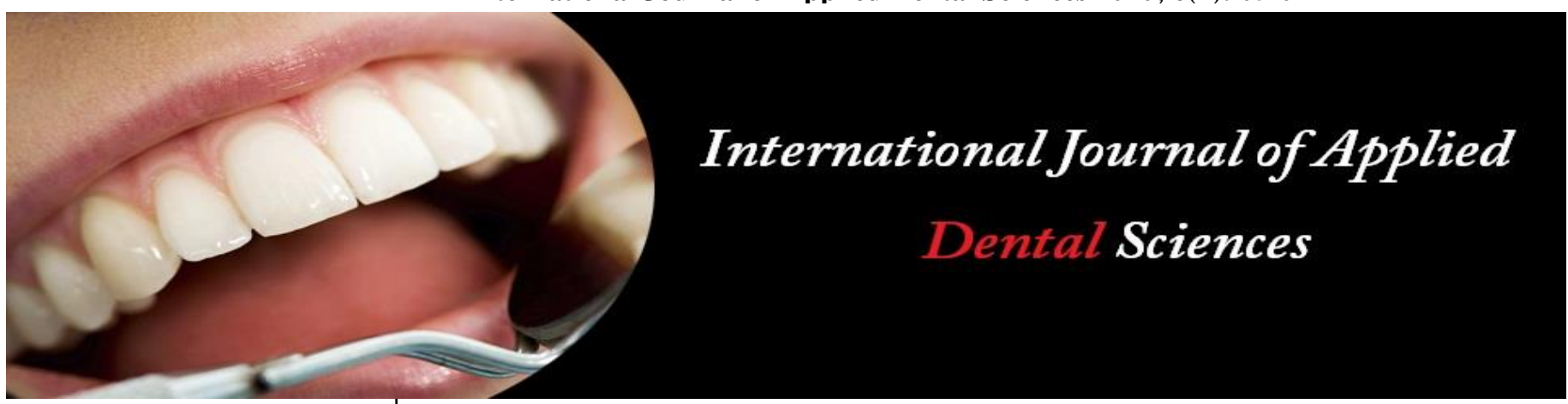

ISSN Print: 2394-7489

ISSN Online: 2394-7497

IJADS 2020; 6(4): 05-07

(C) 2020 IJADS

www.oraljournal.com

Received: 21-07-2020

Accepted: 05-09-2020

Dr. Ruchika Gupta Dewan Professor, Department of

Conservative Dentistry and

Endodontics, ITS Dental College,

Hospitals and Research Centre,

Knowledge Park III, Greater

Noida, Uttar Pradesh, India

Dr. Unnavi Chauhan

Student, Department of

Conservative Dentistry and

Endodontics, ITS Dental College,

Hospitals and Research Centre,

Knowledge Park III, Greater

Noida, Uttar Pradesh, India
Corresponding Author:

Dr. Ruchika Gupta Dewan,

Professor, Department of

Conservative Dentistry and

Endodontics, ITS Dental College,

Hospitals and Research Centre,

Knowledge Park III, Greater

Noida, Uttar Pradesh, India

\section{Foreign body impaction in the maxillofacial region: A case report}

\section{Dr. Ruchika Gupta Dewan and Dr. Unnavi Chauhan}

DOI: https://doi.org/10.22271/oral.2020.v6.i4a.1038

\section{Abstract}

This article describes the presence of foreign bodies which are asymptomatic in nature in the orofacial soft tissue spaces. The patient had reported to the Department of Conservative Dentistry and Endodontics with sensitivity as the chief complain in the lower right back tooth region. Clinical Examination were suggestive of generalised attrition in relation to \#46. Radiographic findings revealed a well defined radioopacity in relation to distal root of \#46. This radiolucency was seen to have moved to the mesial root when another radiograph of the same tooth was taken. An orthopantomograph and CBCT was then taken to study the case better which apparently showed around 12 such radio-opacities lodged in the oral cavity with the patient being absolutely asymptomatic of it. The provisional diagnosis of foreign bodies embedded in the soft tissue was considered.

Keywords: Foreign body, gunshot wound, maxillofacial

\section{Introduction}

Foreign bodies are objects that are not native to the human body. They may be inserted, ingested or deposited in the human body accidentally ${ }^{[1,2]}$. Foreign bodies can get inserted into the body cavities by various ways, or can also get inserted into the body by accidental trauma or injuries. Road accidents, physical abuse or fights, and gunshot wounds are a common cause for traumatic foreign bodies ${ }^{[3,4]}$.

The common drug based lesions include deposition of materials used during certain conservative or endodontic procedures, amalgam and graphite tattoos, granulomas and introduction of dental materials and instruments mistakenly during dental procedures. ${ }^{5}$ Pieces like metal based objects, wood, twigs, splinters, glass based particles, brushes with tooth brushes being more common, fish hooks, caps like bottle caps or pen caps with spring, and fragments of smoking pipes are some foreign bodies that can have a high chance of impaction in the maxillofacial region ${ }^{[6,7]}$.

Foreign bodies can remain dormant in the soft tissue for years without causing any damage to the adjacent structures ${ }^{[8,9]}$. However, some of these foreign bodies can produce some kinds of inflammatory reactions and be a prominent source of infection. Hence their identification and removal from the soft tissue is often necessary to prevent any further damage.

This paper describes about a case with impacted foreign bodies in the orofacial soft tissue spaces which was asymptomatic in nature.

\section{Case Report}

\section{Chief complaint}

A 60-year old male patient reported to the Department of Conservative Dentistry and Endodontics with the chief complaint of sensitivity in the lower right back tooth region since 10 days.

Extra-oral examination

No Abnormality detected. 


\section{Intra-oral examination}

- Generalised attrition with sensitivity in relation to \#46 (Fig 1)

- No carious lesions

- No pain on palpation and percussion

- No swelling

- Immediate response observed on thermal (cold) vitality test

\section{Radiographic examination}

- Radiographic examination revealed a well-defined radioopacity in relation to distal root of \#46 (Fig 2). To rule out any radiographic errors another radiograph of the same region was taken in which the radio opacity moved to the mesial root raising the suspicion of a foreign body (Fig 3).

- An orthopantomograph was then taken to study the case better which apparently revealed around 12 such radioopacities lodged in the oral cavity. However, the patient was absolutely asymptomatic. (Fig 4).

On further questioning, the patient then mentioned of being a victim of bullet injury 18 years back. The patient was not on any kind of medication and was asymptomatic for the same.(Fig 5,6)

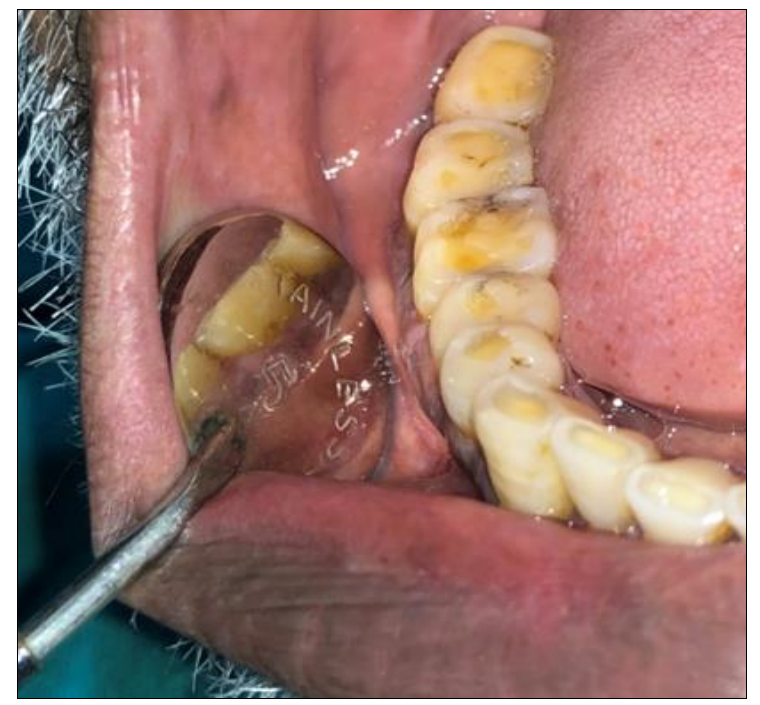

Fig 1.

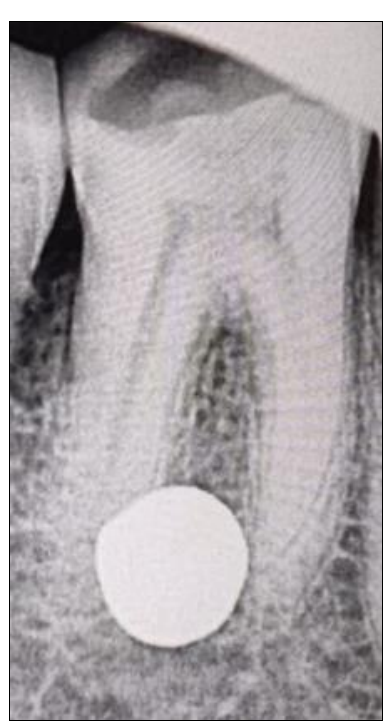

Fig 2.

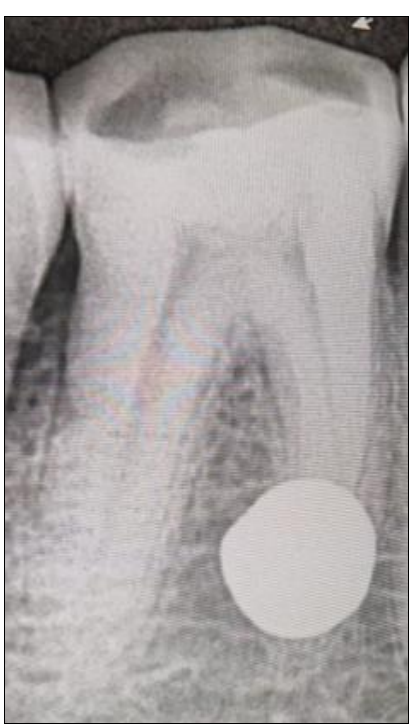

Fig 3.

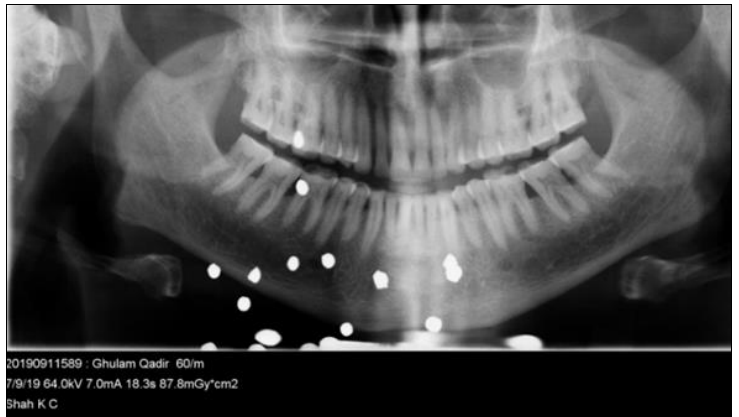

Fig 4.

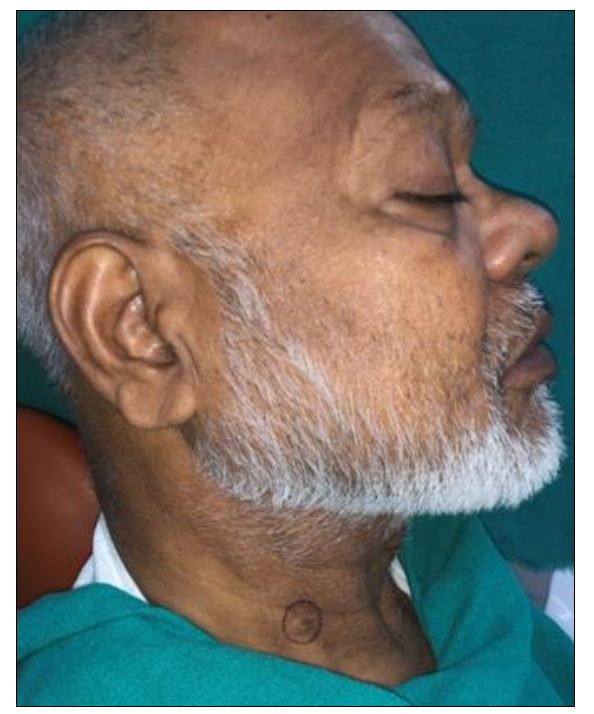

Fig 5.

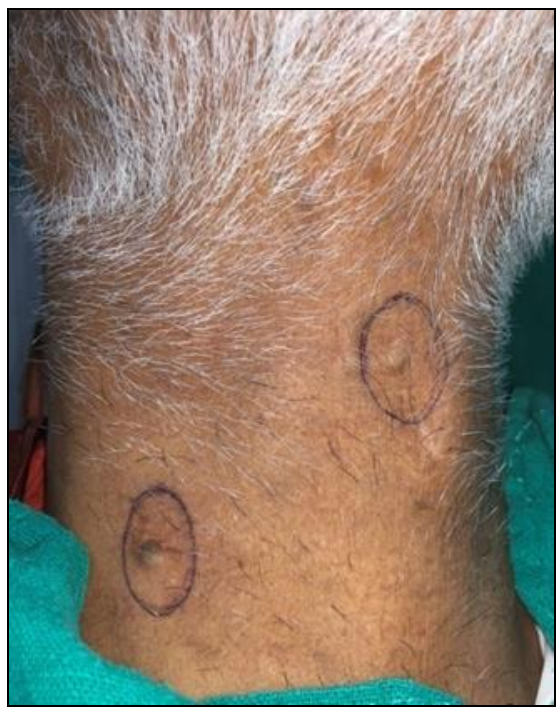

Fig 6.

\section{Diagnosis}

Therefore, the provisional diagnosis of foreign bodies embedded in the soft tissue was made.

\section{Discussion}

Foreign bodies which are found lodged in the oral or the maxillofacial region could be a result of traumatic injuries or may be due to the drugs that are being taken. Foreign objects can trigger inflammatory reactions and can be a potential source of pain and infection ${ }^{[10,11]}$.

Frequently, it is difficult to detect these impacted foreign bodies clinically, and they pose a diagnostic challenge. The visibility of different materials on radiographs is highly 
dependent on the object's ability to attenuate-rays or absorb the rays. Foreign bodies are visualized, mostly depending on their radio density and the area associated with the soft tissue in which they are lodged ${ }^{[12]}$. Intraoral peri-apical X-ray, Cone Beam Computed Tomographic (CBCT) scan, Ultrasonography, Orthopantomographs and Magnetic Resonance Imaging (MRI) are some diagnostic tools helpful in confirming the presence, location, size, and shape of the foreign bodies that are present in the soft tissue ${ }^{[13]}$. Plain radiographs have $69-90 \%$ success rate of detection for most of the metallic foreign bodies while a success rate of $71-77 \%$ is seen for glass cases. Apparently, very little or no information is available for the identification of most of the organic materials such as wood $(0-15 \%)^{[14]}$.

The orofacial soft tissue spaces are the anatomic spaces present between the deep fascial layers bounded by bones, muscles or salivary glands filled with loose connective tissue which are known to be very potent for foreign body impactions. These spaces have been classified into the suprahyoid and infrahyoid spaces in most of the literature. The impaction of any foreign body induces an inflammatory reaction, resulting in all these space being invaded by inflammatory enzymes mainly aiming for healing with the formation of inflammatory exudates subsequently.

This report describes the case of retained asymptomatic foreign bodies in an adult patient which subsequently alerts the clinicians to consider the possibility of some foreign bodies being present in the oral and maxillofacial regions. The patient was, however, unaware of the foreign bodies and was completely asymptomatic of it. It was only observed on routine radiographic examination which was then confirmed with the help of orthopantomograph and CBCT. This case report highlights the importance of a thorough and systematic intra-oral examination.

\section{Conclusion}

Though the foreign bodies present were asymptomatic at the time of examination, these retained foreign bodies are capable of causing inflammation, abscess formation as well as chronic pathologies including granulomatous tissue reaction, fistula formation and osteomyelitis if unnoticed but there is a very high possibility that they won't cause any harm to the patient and lie dormant as can be seen in the case that has been discussed.

\section{References}

1. Hunter TB, Talijanovic MS. Foreign Bodies. Radiographics. 2003; 23:731-757.

2. Mishra I, Karjodkar F, Sansare K et al. Foreign body impaction in oral cavity. Int J Health Sci. Res. 2016; 6(9):486-490.

3. Santos Tde S, Melo AR, de Moraes HH, Avelar RL, Becker OE, Haas OL, Jr et al. Impacted foreign bodies in the maxillofacial region-diagnosis and treatment. $\mathrm{J}$ Craniofac Surg. 2011; 22:1404-8.

4. Ramya Vinayagam, Bagavad Gita, Sajja Chandrasekaran, Afreena Imami Nazer. Traumatic impaction of foreign body in the mucobuccal fold of lower anterior region in the oral cavity: A chance finding. J Indian Soc Periodontol. 2015; 19(3):339-341.

5. Sumanth KN, Boaz K, Shetty NY. Glass embedded in labial mucosa for 20 years. Indian J Dent Res. 2008; 19:160-1.

6. Khandelwal P, Dhupar V, Akkara F, Hajira N. Impacted foreign bodies in the maxillofacial region-A series of three cases. J Cutan Aesthet Surg. 2018; 11:237-40.

7. Khan I, Singhal A, Singh A. Management of foreign bodies in the maxillofacial region: Diagnostic modalities, treatment concepts with report of 2 cases. J Head Neck Physicians Surg. 2015; 3:15-22.

8. Aregbesola SB, Ugboko VI. Unusual foreign bodies in the orofacial soft tissue spaces: A report of three cases. Niger J Clin Pract. 2013; 16:381-5.

9. Ebner F, Tolly E, Tritthart H. Uncommon intraspinal space occupying lesion (foreign body granuloma) in the lumbosacral region. Neuroradiology. 1985; 27:354-6.

10. Ahmet altan, Ibrahim Damlar, Soydan Kiliç, Berk Turgay. Unusual Foreign Bodies in the Oral Cavity: A Report of Three Cases. Sch. J Dent. Sci. 2015; 2(2A):126-129.

11. Manthey DE, Storrow AB, Milbourn JM, Wagner BJ; Ultrasound versus radiography in the detection of softtissue foreign bodies. Ann Emerg Med. 1996; 28(1):7-9.

12. O'Brien DP, Fantasia JE, Miller AS. Unusual foreign body presenting as a palatal tumor: Case report. Pediatr Dent. 1988; 10:226-7.

13. Altan A, Damlar I, Kilic S, Turgay B. Unusual foreign bodies in the oral cavity: A report of three cases. Sch J Dent Sci. 2015; 2:126-9.

14. de Santos TS, Melo AR, de Moraes HH, Avelar RL, Becker OE, Haas OL Jr, et al. Impacted foreign bodies in the maxillofacial region-diagnosis and treatment. J Craniofac Surg. 2011; 22:1404-8. 